\title{
2006-2007 YILLARI ARASINDA KÜLTEPE KAZILARINDA ELE GEÇEN SİKKE BULUNTULARI
}

\author{
Zeynep Çizmeli Öğün
}

\begin{abstract}
Anahtar Kelimeler: Kültepe $\bullet$ Kaniş $•$ Karum $\bullet$ Sikke • IV. Ariarathes,
Mots de clés: Kültepe $\bullet$ Kanish $•$ Karum $\bullet$ Monnaies $•$ Ariarathes IV.
\end{abstract}

\section{Özet:}

Kültepe Kaniş Karum’unda 1948 yllından itibaren Prof. Dr. Tahsin Özgüç yönetiminde yürütülen kazılarda Asur Ticaret Kolonileri Çağında en parlak dönemini yaşamış olan kente ait birçok eser gün 1şığına çıkarılmıştır. 2006 yılından itibaren Prof. Dr. Fikri Kulakoğlu'nun başkanlığında sürdürülen yeni dönem kazılarında ise, hem Tepe'nin, hem de Karum'un stratigrafisinin tamamlanabilmesi için "geç" dönem buluntuların incelenmesi gündeme gelmiştir. Bu makalede Şehir Suru, Nekropol ve Karum Alanlarında gerçekleştirilen kazılarda ele geçen sikkeler tanıtılmaktadır. Bu sikkelerden 4 tanesi Hellenistik, 5 tanesi Roma ve 1 tanesi de Bizans dönemine tarihlenir ve kentin en son sahiplerinin birer sessiz tanığıdır.

\section{Resumé:}

Les fouilles archéologiques du Kanis-Karum à Kültepe poursuivies depuis 1948 sous la direction de Prof. Dr. Tahsin Özgüç ont mis à jour des vestiges importantes, comme le fameux Palais de Warshama, les temples de l'époque de la colonisation commerciale assyrienne. Afin de compléter leur stratigraphie, la nouvelle mission archéologique, sous la direction du Prof. Dr. Fikri Kulakoğlu depuis 2006, a concentré son travail aussi sur les trouvailles " tardives ». Cet article présente des monnaies, qui ont été mises au jour pendant les travaux sur les murailles de la cité, de la nécropole et de la zone de «Karum». Parmi ces monnaies, nous avons recensé 4 monnaies hellénistiques, 6 monnaies romaines et 1 monnaie byzantine.

Kültepe Kaniş-Karumu'nda 1948 yilında Prof. Dr. Tahsin Özgüç tarafindan başlatılan ilk sistemli kazılar, 1955 yllından itibaren höyükte de sürdürülmüştür ${ }^{1}$. Höyükteki kazılar Prehistorik Çağlarda başlayan yerleşimin Asur Ticaret Kolonileri Çağı'ndan sonra zayıfladığını göstermektedir. Uzunca bir aradan sonra tekrar yerleşilen Tepe'de ise, Demir Devri'ne tarihlenen yerleşim katlarının, daha sonraki devirlerde inşa edilen çeşitli yapılar tarafından büyük ölçüde tahrip edildiği anlaş1lır.

\footnotetext{
1 Özgüç 1999, 2.
} 
Son yapılaşma evresinden günümüze kalmış en önemli kalıntı ise Tepe'nin yüksek kenarlarının altındaki Hellenistik ve Roma çağlarına tarihlenen şehir surudur. Ancak, surların işaret ettiği çağlarda Kültepe, T. Özgüç̧ün de belirttĭği gibi yavaş yavaş eski önemini kaybetmeye başlayıp, giderek Kaisareia'nın gölgesinde kalmış küçük bir şehir görünümüne bürünmüştür ${ }^{2}$. $\mathrm{Bu}$ düşünceyi arkeolojik bulgular da desteklemektedir. 1948-2006 yılları arasında ele geçen Hellenistik ve Roma Dönemi eserleri Asur Ticaret Kolonileri Dönemi'ne kıyasla çok sinırlıdır. Bu döneme işaret eden eserler arasinda 1967 ve 1973 yıllarında gerçekleştirilen kazılarda bulunan sikkeler ${ }^{3}$ ve Tepe'de bulunan ve üzerinde bir "panter avının" betimlendiği M.Ö. 3. yy. sonu - 2. yy'ın ilk yarısına tarihlenen amphora en taninan eserlerdir ${ }^{4}$.

Çalışmamıza konu olan eserler ise kentin son evrelerine 1şık tutacak olan sikke buluntularıdır. Hellenistik Dönem ve sonrasına tarihlenen 11 adet sikke 2006 yilından itibaren Prof. Dr. Fikri Kulakoğlu başkanlığında yürütülen kazılarda ele geçmiştir ${ }^{5}$. Buluntular, Şehir surunun incelenmesi, Aşağ Şehirde yer alan Mezarların kazılması ve Tepe'de yapılan yeni dönem çalışmaları sırasında belirli arkeolojik kontekstte bulunmuştur. Restorasyon ve konservasyon çalışmaları Anadolu Medeniyetleri Müzesi restoratörlerinden Latif Özen ve İlknur Eryıldırım tarafından tamamlanmıştır ${ }^{6}$. 07-KT-32/3 nu-

\footnotetext{
Özgüç 1999, 4.

Taner 1974.

Zoroğlu 1981, 251 = Özgüç 1971, 29-31, Lev. XXX.

Kültepe Kazıları Başkanı Prof. Dr. Fikri Kulakoğlu'na, kazılarında ele geçen "geç" dönem sikke buluntularını incelemem için gereken izni verdiği için ve Kültepe Tarihinde bilinmeyenleri aydınlatmasındaki hassasiyetinden dolayı içten teşekkürlerimi bir borç bilirim.

6 Özverili çalışmalarından dolayı kendilerine teşekkür ederim.
}

maralı sikke hariç diğer sikkeler alçı kalıbından belgelendirilmiştir. Korunma durumu bu sikkenin alçı kalıp alınmasına izin vermemektedir. Metin sonunda yer alan levhada ise, her sikkenin özgün boyutuna sadık olarak çekilen fotoğrafları yer alır ${ }^{7}$ ve bu sikkelerin numarası ise ön yüz ve arka yüz betimlerinden sonra yer alan sikke bilgilerinin içinde verilmiştir. Sikkelerin ağırlı̆̆1, çapı ve yönünden sonra ise Kültepe Kazılarına ait Buluntu Envanter Numarası ile Kazı Envanter Numarası ayrıca belirtilmiştir.

\section{KATALOG}

\section{HELLENİSTIK DÖNEM SİKKELERİ}

İskender Sikkesi (M.Ö. 3. yy.)

Ö/ Aslan postlu Herakles başı, sağa.

A/ Tahtında oturan Zeus, sola. Sağ elinde kartal tutmakta. Zeminde, çelik kalem darbı.

1- AR, 3,57gr, 16,7 mm, 12, Bul No: 07-KT-K.145

= Env. No: 2007/k/02/07/025/M082

\section{Kappadokia Kralı IV. ARIARATHES} EUSEBES (M.Ö. c. 220-163)

Ö/ Kral IV. Ariarathes'in diadem'li başı, sağa.

A/ Athena ayakta, sola. Sol elinde mızrak sağ elinde kral ismini taçlandıran Nike tutmakta. Zeminde,

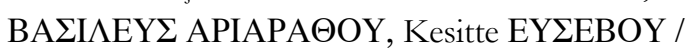

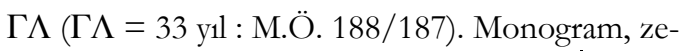
minde: Nike'nin altında $\uparrow$ î, ismin sağında

2- AR, 3,44gr, 18,8 mm, 10, Bul No: 07-KT-K.32/1

= Env. No: $2007 / \mathrm{t} / 00 / 00 / 001 \mathrm{a}$

Ref. Ön yüz Simonetta 1977 Cat no 18 b Plate 2,8 (benzer)

Ö/ Kral IV. Ariarathes’in diadem'li başı, sağa

\footnotetext{
Dicle Üniversitesi Fen ve Edebiyat Fakültesi Arkeoloji Bölümü Araş. Gör. Aytaç Coşkun ve Ankara Üniversitesi Dil ve Tarih Coğrafya Fakültesi Klasik Arkeoloji Anabilim Dalı Araş. Gör. Canan Özbil Serin'e görsel belgelendirme konusundaki yardımlarından dolayı teşekkür ederim.
} 
A/ Athena ayakta, sola. Sol elinde mızrak sağ elinde Nike tutmakta. Nike kral ismini taçlandırmakta. Zeminde,

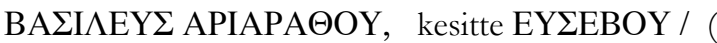
tarih okunamiyor). Monogram, zeminde: Nike'nin altında 㒳, ismin sağında $\Gamma$.

3- AR, 3,38gr, 17 mm, 12, Bul No: 07-KT-K.32/2 = Env. No: 2007/t/00/00/001b

Ref. Ön yüz Simonetta 1977 Cat no 18 b Plate 2,8 (benzer)

Ö/ Kral IV. Ariarathes'in diadem'li başı, sağa

A/ Athena ayakta, sola. Sol elinde mızrak sağ elinde Nike tutmakta. Nike kral ismini taçlandırmakta. Zeminde,

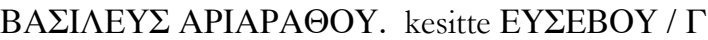

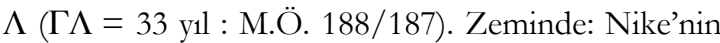
altında 龟, ismin sağında $H$.

4- AR, 3,6gr, 19,6 mm, 12 Bul No: 07-KT-

K.32/3 = Env. No: $2007 / \mathrm{t} / 00 / 00 / 001 \mathrm{c}$

Ref. Simonetta 1977 Cat no 20a

\section{ROMA İMPARATORLUĞU RESMİ SİKKE- LERİ}

\section{Constantinus (M. S. 321-337)}

\section{S. 330-335}

Ö / CONSTANTI-NVS MAX AVG. İmparator'un çelenkli, zırhlı büstü, sağa.

A/ GLOR-IA EXERC-ITVS. Karşıllklı ayakta duran iki asker, sağ ellerinde mızrak taşımakta. Aralarında iki adet lejyon alemi (standart) durmakta. Kesitte, SMNB.

5- AE, 2,49 gr, 17,3 mm, 5, Bul No: 06-KT-K.211= Env. No: $2006 / \mathrm{k} / 02 / 05 / 211$

Ref. Hill-Kent 1965 Type no. 1116-7 s. 26

(Nicomedia darphanesi)

\section{Constantius (M. S. 348-350)}

Ö/ DN CONSTAN [ ] -[ ]. II. Constantius'un, diadem'li, zırhlı büstü, sağa

A/ Çelengin içinde, VOT/ XX/MVLT/ XXX.
6- AE, 1,21 gr, 15 mm, 12, Bul No: 06-KT-K.191= Env. No: 2006/k/02/04/191

Ref. Hill-Kent 1965 Type 967(benzer) s. 23

\section{Honorius (M. S. 395-423)}

\section{S. 395/402}

Ö/ D N HONORIVS P F AVG, İmparator Honorius'un, inci diadem'li, zırhlı büstü, sağa.

A/ SALVS R[EI-PVBLICAE], Victoria, sağa yönelmiş, zafer sancağ (trophe) taşımakta ve solundaki tutsağ1 sürüklemekte.

7- AE, 1,59 gr, 14 mm, 6, Bul No: 06-KT-K.237= Env. No: $2006 / \mathrm{k} / 02 / 07 / 237$

Ref. Kent 1994 Type 1237 s. 322 (Aequileia darphanesi)

Honorius - Arcadius (M.S. 395-402, 395-408)

Ö/ İmparator baș1.

A/ Cepheden ayakta duran ve sağ elindeki mızrağa dayanmıș asker kıyafetli bir İmparator figürü, sağda Victoria ayakta ve sola dönük (Tip Virtus Exerciti)

8- AE, 1,56 gr, 13,8 mm, 12? Bul No: 06-KT-

K.252= Env. No: 2006/k/02/09/252

Ref. Kent 1994 Type 2 Virtus Exerciti

Ö/ İmparator baş1.

A/ Cepheden ayakta duran ve sağ elindeki mızrağa dayanmış asker kıyafetli bir İmparator figürü, sağda Victoria ayakta ve sola dönük.

9- AE, 2,2 gr, 14,8 mm, 10, Bul No: 07-KT-K.67= Env. No:2007/k/02/01/01

Ref. Kent 1994 Type 2 Virtus Exerciti

M. Ö. 3 - M. S. 2. yy'a ait sikke

Ö/ Okunamiyor.

A/ Okunamiyor.

10- AE, 3,69 gr, 20 mm, 10, Bul No: 06-KT-K.01= Env. No: 2006/Yüzey/1

\section{BİZANS DÖNEMİ SİKKELERİ}

I. Anastasius (M.S. 1 Nisan 491- 1 Temmuz 518)

Ö/ [ ]T ANASTA-SIVS İmparator I. Anastasius'un büstü sağa, diadem'li zırhlı ve paludamentum'lu.

A/ M ; solda haç ; sağda Off. harfi : $\ominus$. 
11- AE, 8,37gr, 26,5 mm, 6, Bul No: 06-KT-

K.276= Env. No: 2006/k/02/09/276

Ref. Bellinger-Grierson 1966 Type 24g I-II s. 24 (Konstantinopolis darbı)

2006 ve 2007 y1llarında Kültepe Kazılarinda ele geçen 11 sikkeden 4 adeti Hellenistik Döneme aittir. Bunların içinden 07-KT-K.145 numaralı gümüş sikke 82 numaralı mezardan ele geçmiş sikkedir. III. Aleksandros'a (İskender) ölümünden sonra Anadolu'da darp edilen, posthumus didrahmi birimindedir. Çok aşınmış olmasından muhtemelen uzun bir süre dolaşımda kalmış olduğunu anlayabiliriz. Ayrıca metal kalitesini kontrol amaçlı arka yüzüne ufak bir müdahele yapıldığı gözlenmiştir ${ }^{8}$. Hellenistik Döneme ait diğer 3 adet sikke, M.Ö. 220163 yılları arasında Kappadokia'da hüküm sürmüş kral IV. Ariarathes Eusebes'a aittir ve Warshama Sarayının batı duvarının önü ile işlevi kazılarla belirlenecek olan "Geç Dönem Yapısı"nın doğu duvarının önünde, birbirine yapışı olarak ele geçmiştir. Bu sikkelerden iki tanesi (07-KT-K.32/1, 07-KTK.32/3) Kral IV. Ariarathes'in hükümdarl1ğının 33. yllında (M.Ö.188/187) darp ettiğgi sikkelerdir. 07-KT-K.32/2 numaralı sikkenin ise arka yüzünde yer alan darp tarihinin okunmamasına rağmen, ön yüzdeki portreden yine aynı kralın hükümdarlığının 30-33 yılları arasında darp edildiğini anlamaktayı ${ }^{9}$.

81967 ve 1973 yıllarında ele geçen 4 sikke de aynı dönemi işaret etmektedir. III. Aleksandros'un ölümünü izleyen dönemde gerçekleştirilen M.Ö. 315 yllı civarlarına tarihlenen III. Aleksandros'un kendisine ait Abydos ve Lampsakos atölyesinde darp edilmiş 2 adet posthumus gümüş sikke (Taner 1974, 591 no 3-4) ile M.Ö. 323-318 yllarında Colophon sikkesinde darp edilmiş III. Philippos'a atfedilen 2 adet gümüş sikke bulunmuştur (Taner 1974, 590-591 no 1-2).

9 IV. Ariarathes'in yine hükümdarlığının 33. yllında (M.Ö.188/187) darp ettiği 7 adet gümüs sikke 1967, 1973 y1lları Kültepe buluntuları arasında yer alır (Taner
Kültepe'de 2006 ve 2007 yillarında ele geçen sikkeler arasında Roma hâkimiyetindeki Anadolu kentlerinin darp ettiği Eyalet Sikkelerinden örnek bulunmamıștır ${ }^{10}$. Ancak Roma İmparatorluğu'nun Resmi Darphanelerine ait 5 adet sikke saptanmıştır. Bu sikkeler Diocletianus Reformu'nu izleyen dönemde darp edilen sikkelerdir ve 20062007 yllarında Karum Alanındaki "Roma Yapısı"nda gerçekleştirilen kazılarda üst dolgu toprağından ele geçmiştir. Aralarından İmparator Büyük Constantinus (06KT-K.211), II. Constantinus (06-KTK.191) ila Honorius'a (06-KT-K.2237) ait birer örnek ve korunma durumları çok düşük olmasına rağmen arka yüzde kullanılan betim sayesinde M.S. 395-402, 395-408 y1ları arasina tarihlendirilen 2 adet sikke (06KT-K.252 ve 06-KT-K.67) kataloğa dâhil edilmiştir. 06-KT-K.01 numaralı sikkenin ise ön ve arka yüzündeki betimler okunamamakta olup, çap1, ağırlığ1 ve kalınlığ1 sayesinde Hellenistik Dönem ila Roma Döneminin ilk iki yüzyılı içinde bir tarihte darp edildiği anlaşılmaktadır.

En geç döneme tarih veren 06-KTK.276 numaralı sikke ise yine Karum Alaninda ele geçen ve Bizans İmparatoru I. Anastasius'un Constantinopolis darphanesinde darp edilen 20 nummi değerindeki sikkedir $^{11}$.

1974, 591-593 no 5-11). Ayrıca M.Ö. 36 - M.S. 17 y1llan1 arasında hüküm sürmüş bir başka Kappadokia kralı Arkhelaos'un 1 adet bronz sikkesi de aynı buluntular arasında kayıtlara geçmiştir (Taner 1974, 593 no 12).

101967 ve 1973 yllları buluntuları arasinda Kaisareia ve Tyana'nın İmparator Marcus Aurelius döneminde darp ettiği toplam 6 adet bronz sikkesi ele geçmiştir (4 adet Kaisareia kenti sikkesi : Taner 1974, 593-594 no 13-16; Tyana : Taner 1974, 594-595 no 17-18).

11 Fakat T. Özgüç, Kültepe-Kaniš/Neša Saraylar ve Mabedleri/The Palaces and Temples of Kültepe-Kaniš/Neša kitabında Selçuklu Sultanı II. Keyhüsrev'in Karum'da düşürülen bir sikkesinden bahseder. Bu sikke ise yüzey 
Bu çalışmada ayrıntıları ile betimlediğimiz bu küçük sikke grubu, 1948 yilından beri düzenli bir şekilde kazılan Kültepe'nin son sakinlerine ait birer belge niteliğindendir. Belirlenen alanlarda gelecek yıllarda gerçekleştirilecek kazılarda bu sikkelerin işaret ettiği dönemlere ait başka buluntuların gün 1ş1ğına çıkarılmasıyla Kültepe'nin terk edilme evreleri hakkında daha fazla bilgiye sahip olunacaktır.

Doç. Dr. Zeynep Çizmeli Öğün Ankara Üniversitesi

Dil ve Tarih Coğrafya Fakültesi

Klasik Arkeoloji Anabilim Dalı

Sihhiye-ANKARA

zeynepogun@yahoo.com

buluntusu olarak Kültepe'nin tüm sikke buluntuları içinde en geç döneme tarihlenen sikkesi olarak kabul edilmelidir: Özgüç 1999, 1-2, Lev. 4, 1. 
2006-2007 Y1lları Arasında Kültepe Kazılarında Ele Geçen Sikke Buluntuları

\section{BİBLIYOGRAFYA}

Bellinger - Grierson 1966 A. R. Bellinger - Ph. Grierson, Catalogue of Byzantine Coins in the Dumbarton Oaks Collection and Whittemore Collection I, Anastasius I to Maurice (491-602) (1966).

Hill - Kent 1965

V. Hill - J P. C. Kent, Late Roman Bronze Coinage AD. 324-498, (1965).

Kent 1994

J. Kent, The Roman Imperial Coinage Vol X. The Divided Empire and the Fall of the Western Parts 395-491 (1994)

Özgüç 1971

T. Özgüç, Demir Devrinde Kültepe ve Civarı/Kültepe and Its Vicinity in the Iron Age TTKY-V, 29 (1971).

Özgüç 1999

T. Özgüç, Kültepe-Kaniš/Neša Sarayları ve Mabedleri/The Palaces and Temples of Kültepe-Kaniš/Neša. TTKY. V, 46 (1999).

Simonetta 1977

B. Simonetta, The Coins of the Cappadocian Kings, Typos II (1977).

Taner 1974

S. Taner, “Kültepe Sikkeleri (1967, 1973)”, Belleten 38, 152, 1974, 583-596.

Zoroğlu 1981

L. Zoroğlu, "Kültepe'de Bulunan Hellenistik Çağa Ait Bir Amphora”, Selçuk. Üniversitesi Edebiyat Fakültesi Dergisi 1, 1981, 239-252. 

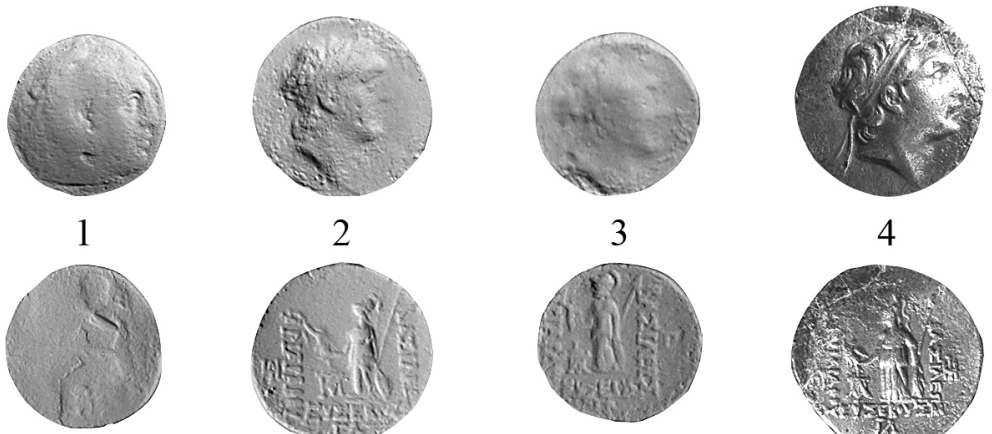

2
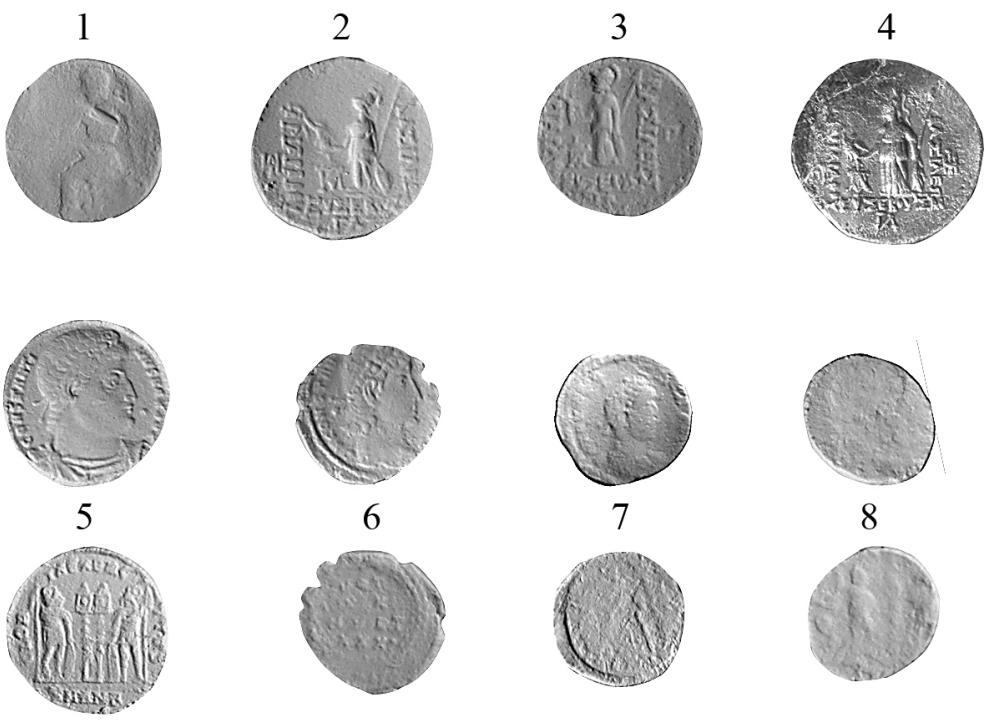

8
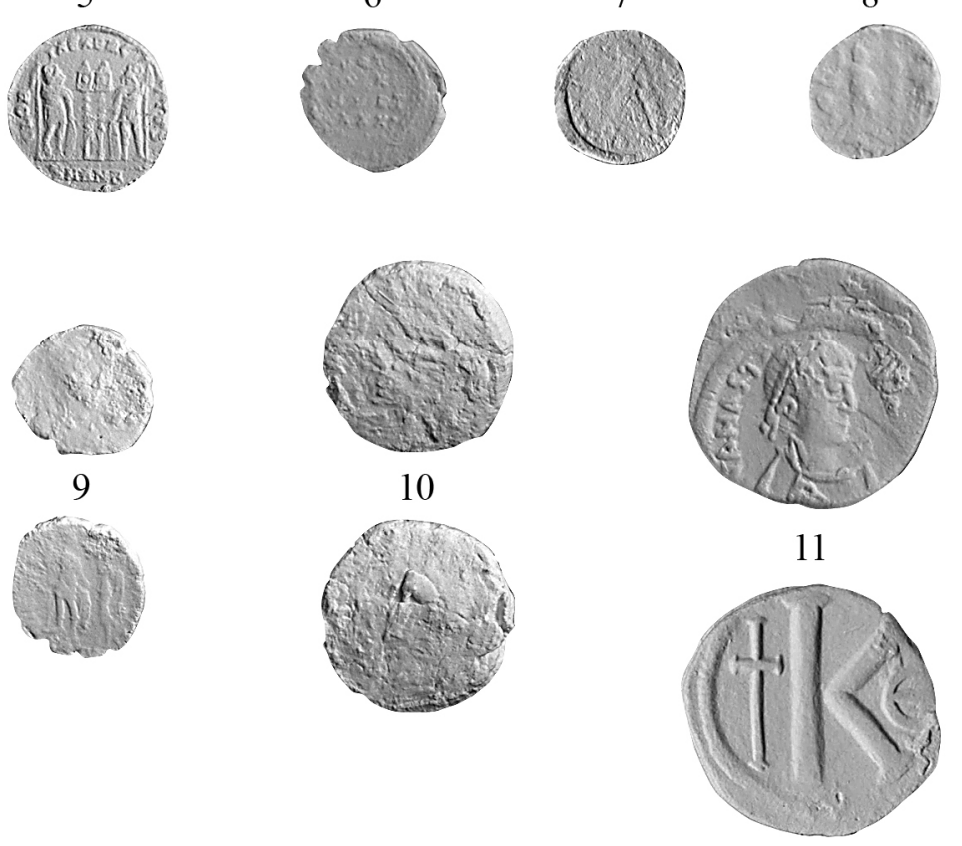